\begin{tabular}{lll}
\hline Bentham OPEN & The Open Parasitology Journal \\
\hline CrossMark & Content list available at: www.benthamopen.com/TOPARAJ/ & DOI: $10.2174 / 1874421401806010052,2018,6,52-62$ \\
\hline Tharsitology \\
lournal
\end{tabular}

RESEARCH ARTICLE

\title{
Susceptibility Status of Aedes aegypti L. Against Different Classes of Insecticides in New Delhi, India to Formulate Mosquito Control Strategy in Fields
}

\author{
Roopa Rani Samal and Sarita Kumar* \\ Department of Zoology, Acharya Narendra Dev College, University of Delhi, Kalkaji, Govindpuri, New Delhi 110019 , \\ India
}

Received: June 4, 2018

Revised: September 3, 2018

Accepted: September 7, 2018

\begin{abstract}
:
Background:

Mosquito control is a major concern throughout the world because of rising cases of mosquito-borne diseases. The outbreak of Zika, Dengue and Chikungunya has caused grave situations raising urgent need to control Aedes aegypti. Moreover, extensive use of synthetic insecticides in mosquito control programs has resulted in high levels of insecticide resistance leading to the use of magnified concentrations, impacting human health and environment adversely. The knowledge about current status of the insecticide susceptibility against Ae. aegypti could help to devise mosquito control strategy.
\end{abstract}

\section{Objective:}

Present study evaluates the larvicidal potential of thirteen insecticides belonging to seven different classes; organochlorines, organophosphates, carbamates, pyrethroids, neonicotinoids, avermectins and secondary metabolites; against early fourth instars of Ae. aegypti.

\section{Materials and Methods:}

The insecticide susceptibility was evaluated as per WHO protocol. Fatality counts were made after $24 \mathrm{~h}$ of exposure; and the $\mathrm{LC}_{50}$, $\mathrm{LC}_{90}$ and other statistical parameters were computed by probit-regression analysis.

\section{Results:}

The data reveals the maximum efficacy of pyrethroids and fenitrothion, with lethal values less than 0.001 ppm. Avermectins, organochlorines and carbamates were moderately toxic, while neonicotinoid posed appreciable toxicity. In contrast, berberine, a secondary plant metabolite was found inefficient. The larvicidal efficacy of tested insecticides against Ae. aegypti was found in the decreasing order of pyrethroids $>$ organophosphates $>$ avermectins $>$ organochlorines $>$ carbamates $>$ neonicotinoids $>$ secondary metabolites.

\section{Conclusion:}

Present investigations explore various toxicants as Dengue vector control agents in order to devise a suitable control strategy for mosquito control in fields.

Keywords: Aedes aegypti, Larvicidal, Insecticides, Resistance, Avermectins, Neonicotinoids.

\footnotetext{
* Address correspondence to the author at the Department of Zoology, Acharya Narendra Dev College, University of Delhi, Kalkaji, Govindpuri, New Delhi 110019, India; Tel: +91-9810309912; Email: saritakumar@andc.du.ac.in
} 


\section{INTRODUCTION}

Mosquito-borne diseases; prevalent in more than 100 countries across the world, infecting over millions of individuals every year at the global level; are among the leading cause of human deaths [1,2]. Aedes aegypti L. is today considered the most threatening vector in the tropics creating a havoc with a range of diseases like Dengue, Yellow fever, Chikungunya and Zika. As per WHO report, currently 47 countries are at the risk of severe Dengue while 60 countries are under the attack of Chikungunya [3]. In recent decades, the incidences of Dengue have grown dramatically around the world. Moreover, under-reporting of actual numbers of Dengue cases and their misclassification has made the disease serious and uncontrollable. According to the recent estimates, human population experiences 390 million Dengue infections per year (95\% credible interval 284-528 million), of which 96 million manifests clinically [4, 5].

Dengue contagion is one of the most probative Aedes-borne viral diseases of humans in tropics. In India, diseases transmitted by Ae. aegypti and Ae. albopictus have shown a significant rise during the last decade. According to the data compiled by the Ministry of Family and Health Welfare, India experienced a total of 1,29,166 cases of Dengue with 245 fatalities in 2016 which substantially increased to 1,53,635 cases in 2017 leading to 226 deaths [6]. In addition, with the recent outbreak of Chikungunya across India with a total of 62,268 cases in 2017, Ae aegypti has taken a huge attention of researchers [6]. Moreover, diseases like Zika are on the rise causing grave situation. Keeping in view the lack of an adequate and successful vaccine against these diseases, control of mosquito vector by large scale larval mortality is the only solution [7].

The most recommended plan to control mosquito-borne diseases primarily lies on mosquito management below threshold level and interrupting their disease-transmission cycle. Various control measures; elimination of their breeding places, use of several biological agents, sterile insect release method, etc.; have been devised and practiced till date [8]. Insecticides belonging to different groups, especially DDT (organochlorine) and malathion (organophosphate) have been in extensive use for the past few decades in vector control programmes in India. Though majorly all the organochlorines are banned by EPA for residential usage due to acute toxicity, they are still in use in agricultural fields [9].

Exploration of new insecticides led to the discovery and application of organophosphates and carbamates in pest control. Gradually, they were also banned by US-EPA as part of the food and quality protection act due to reports of ground water contamination in California [10]. Malathion used extensively in agriculture, residential landscaping and in eradication of mosquitoes was replaced by novel pyrethroids due to adverse environmental impact [11]. Subsequently, synthetic pyrethroids were employed for Indoor Residual Spraying (IRS) in areas with multiple insecticide-resistant vectors, for the treatment of mosquito nets (Insecticide-Treated Nets or ITNs) and then for manufacturing of longlasting insecticidal nets (LLINs) [12 - 14].

Pyrethroids, synthetic analogs of pyrethrins isolated from the flowers of Chrysanthemum have been labeled as safe by WHO for use in vector control programs [15 - 17]. However, continued and random use of pyrethroids has resulted in the development of resistance in mosquito vectors and threat to aquatic life $[18,19]$. Consequently, new insecticides were explored and pyrethroids were replaced by neonicotinoids and other compounds of novel chemistry. Till date, no report of high levels of neonicotinoid resistance and cross-resistance against them has been cited in literature [20]. In general, neonicotinoids are found to be of very low toxicity to mammals and non-target organisms, rendering them as efficient alternates for mosquito management [21]. Nowadays, avermectins are also being explored as broad-spectrum pesticides reported to possess efficacy against a variety of arthropods [22] and nematodes [23, 24].

Devising a suitable mosquito management program requires the latest reports on the susceptibility status of that particular species against different insecticides in use. As it is well known that injudicious pesticide applications against that insect pest often leads to environment pollution and harmful effects on human and non-target species; it becomes imperative to evaluate the toxicities of different insecticides to formulate control strategies.

Lack of baseline susceptibility data, continued rise in Aedes-borne diseases and increase in the insecticide resistance in Ae. aegypti, has forced us to assess the current insecticide susceptibility status in the larvae of Ae. aegypti. Present investigations, thus attempts to take a comprehensive view of susceptibility in larvae of Dengue fever vector against OCls, OPs, Carbamates, Synthetic pyrethroids, Neonicotinoids, Avermectins and Secondary metabolites currently utilized against them. The study will provide a better understanding and will give a clear picture about the susceptibility of Ae. aegypti towards both traditionally used and newly introduced insecticides. It will help to devise a suitable mosquito control strategy which is of prime importance nowadays. 


\section{MATERIALS AND METHODS}

\subsection{Culture of Mosquitoes}

Dengue fever mosquitoes, Ae. aegypti, were collected from different areas of New Delhi (Fig. 1). The colony of Ae. aegypti was maintained in an insect rearing laboratory under controlled conditions of $28 \pm 1^{\circ} \mathrm{C}, 80 \pm 5 \% \mathrm{RH}, 14 \mathrm{~h}$ of light and $10 \mathrm{~h}$ of darkness [25]. Adults kept in clothed cages were fed on sugary juice by supplying them raisins soaked in water. Female mosquitos were provided with occasional blood meals for egg maturation by keeping albino rat in the cage. The eggs were collected in an ovitrap lined with Whatman filter paper strips which were then transferred into the enamel trays filled with at least 1.5-2.0 L of dechlorinated water. The hatched larvae were fed on powdered dog biscuits and yeast in a ratio of 3:1 [26]. The pupae were collected on regular basis and were kept in clothed cages for adult emergence.

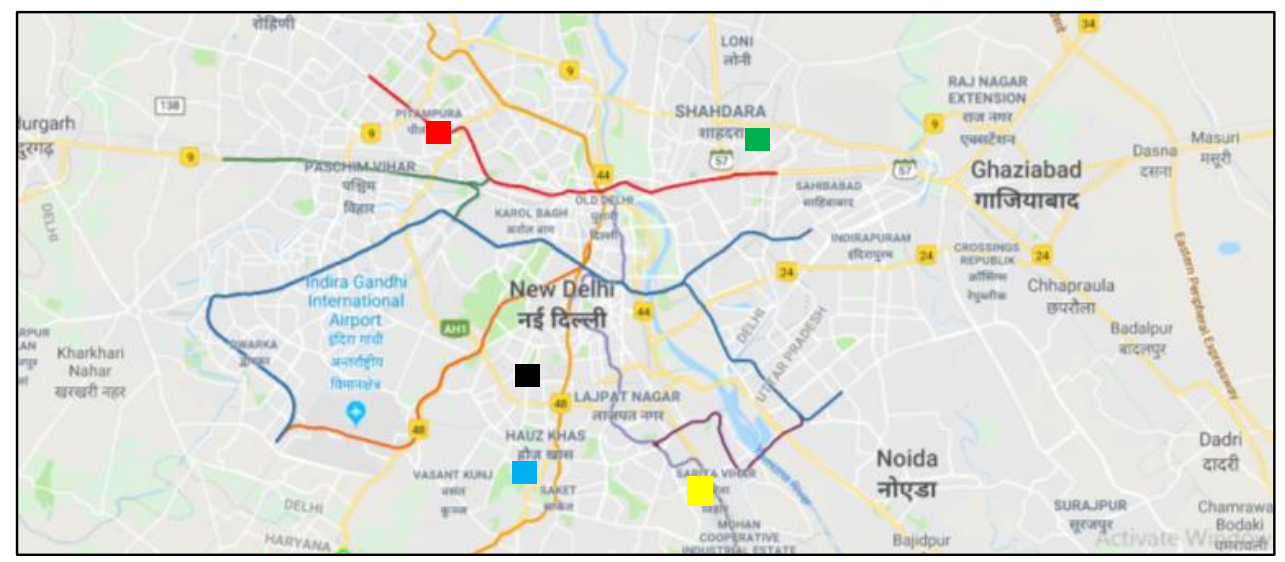

Fig. (1). Areas selected in Delhi for the collection of Aedes aegypti larvae Different sites in New Delhi and NCR for collection of Aedes aegypti Larvae: - Pitampura [Latitude, Longitude (28.705493, 77.132341) $28^{\circ} 42^{\prime} 19.8^{\prime \prime} \mathrm{N}$ and $77^{\circ} 07^{\prime} 56.4^{\prime \prime} \mathrm{E}$; 口 Shahdara [Latitude, Longitude $(28.700001,77.291662) 28^{\circ} 42^{\prime} 00.0^{\prime \prime} \mathrm{N}$ and $77^{\circ} 17^{\prime} 30.0^{\prime \prime} \mathrm{E}$ ]; $\quad$ Saket [Latitude, Longitude (28.521625, $77.213702) 28^{\circ} 31^{\prime} 17.9^{\prime \prime} \mathrm{N}$ and $\left.77^{\circ} 12^{\prime} 49.3^{\prime \prime} \mathrm{E}\right]$; $\quad$ Sarita Vihar [Latitude, Longitude $(28.531703,77.288247) 28^{\circ} 13^{\prime} 54.1^{\prime \prime} \mathrm{N}$ and $\left.77^{\circ} 17^{\prime} 17.7^{\prime \prime} \mathrm{E}\right] ; \mathbf{\square}$ Lodhi Colony [Latitude, Longitude (28.579848, 77.215736) $28^{\circ} 34^{\prime} 47.5^{\prime \prime} \mathrm{N}$ and $77^{\circ} 12^{\prime} 56.7^{\prime \prime} \mathrm{E}$ ]

\subsection{Preparation of Insecticidal Solutions}

The susceptibility of Ae. aegypti larvae were conducted against seven groups of insecticides. The details of thirteen insecticides investigated are presented in Table 1. Among these; Organochlorines (lindane, endosulphan), Organophosphates (malathion, fenitrothion) and Pyrethroids (deltamethrin, alpha-cypermethrin, lambda-cyhalothrin, permethrin) were procured from M/s Aimco Insecticides, Mumbai India; whereas rest of the insecticides; acetamiprid, carbofuran, fenobucarb, emamectin benzoate and berberine were obtained from M/s Sigma Aldrich.

Table 1. Insecticides evaluated for larvicidal activity against Aedes aegypti (Data procured from IRAC).

\begin{tabular}{|c|c|c|c|c|}
\hline Insecticide & IUPAC name & Structure & Mode of action & $\begin{array}{c}\text { Percent } \\
\text { purity }\end{array} \mid$ \\
\hline \multicolumn{5}{|c|}{ Organochlorines } \\
\hline Lindane & (1r,2R,3S,4r,5R,6S)-1,2,3,4,5,6-hexachlorocyclohexane & & $\begin{array}{l}\text { Inhibit gamma- } \\
\text { Aminobutyric acid } \\
\text { (GABA) chloride } \\
\text { ionophore complex }\end{array}$ & 99.5 \\
\hline Endosulphan & 6,7,8,9,10-Hexachloro-1,5,5a,6,9,9a-hexahydro-6,9-methano-2,4,3-benzodioxathiepine-3-oxide & & $\begin{array}{l}\text { Inhibit gamma- } \\
\text { Aminobutyric acid } \\
\text { (GABA) chloride } \\
\text { ionophore complex }\end{array}$ & 96.5 \\
\hline \multicolumn{5}{|c|}{ Organophosphates } \\
\hline Malathion & Diethyl 2-[(dimethoxyphosphorothioyl) sulfanyl] butanede & & $\begin{array}{l}\text { Inhibit acetylcholine } \\
\text { esterase enzyme }\end{array}$ & 95.0 \\
\hline Fenitrothion & O,O-Dimethyl O-(3-methyl-4-nitrophenyl) phosphorothioatek & & $\begin{array}{l}\text { Inhibit acetylcholine } \\
\text { esterase enzyme }\end{array}$ & 96.7 \\
\hline
\end{tabular}




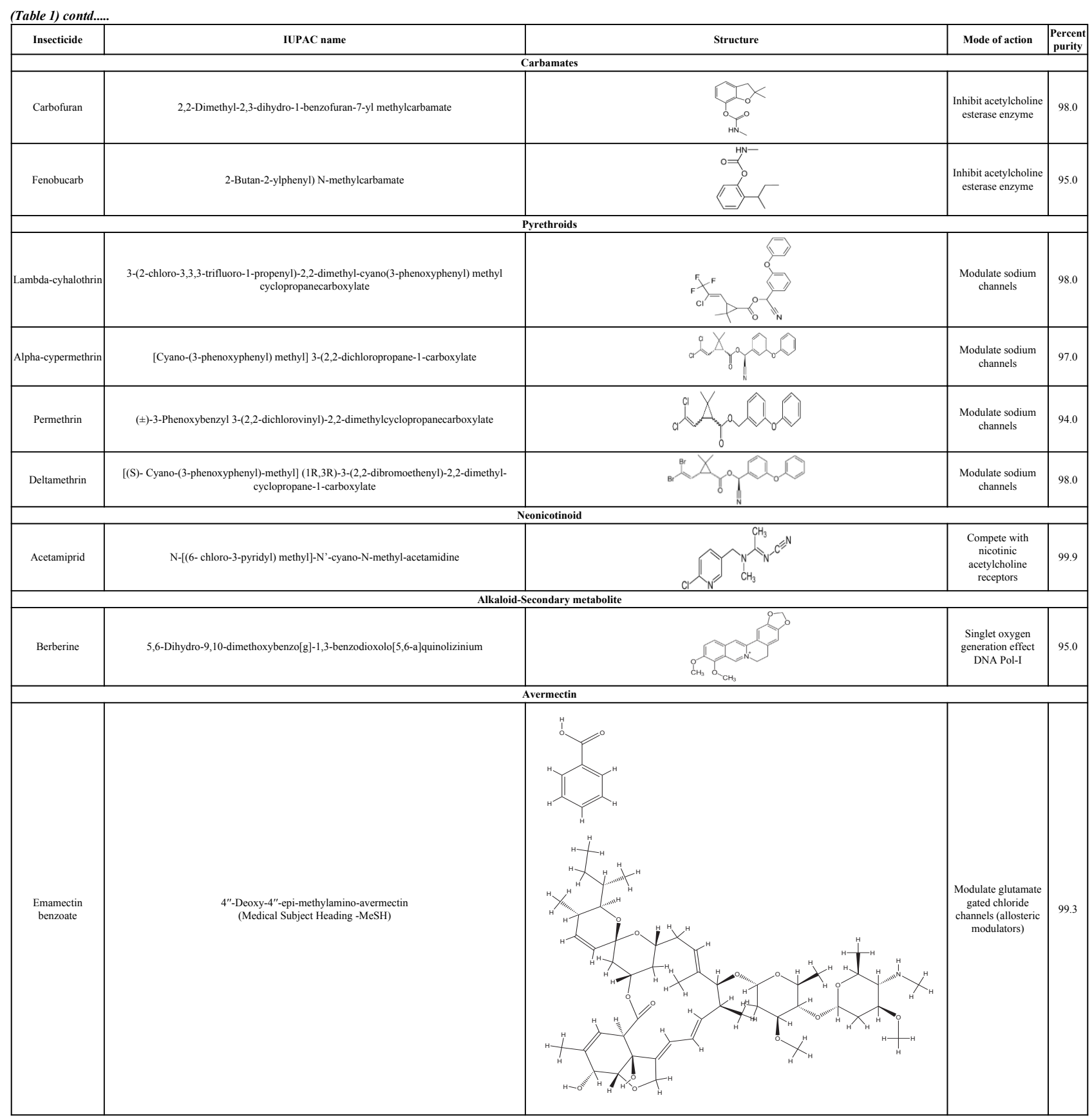

All the insecticides were diluted in ethanol (eMerck) and desired stock concentrations were prepared. Each solution was stored at $4^{\circ} \mathrm{C}$ and assessed for their efficacy against larvae of Dengue fever vector.

\subsection{Larvicidal Bioassays with Insecticides Against Aedes aegypti}

The larvicidal efficacy of the insecticides against Ae. aegypti early fourth instars were assessed as per WHO protocol [25] with few modifications. The graded series of each insecticide was prepared to conduct the bioassay. For each bioassay, a total of 25 early fourth instar larvae of Ae. aegypti were taken in a bowl filled with $89 \mathrm{~mL}$ of dechlorinated water. These were then transferred to glass beakers containing $110 \mathrm{~mL}$ of dechlorinated water and $1 \mathrm{~mL}$ of the particular concentration of an insecticide [27, 11]. For each concentration, three replicates were run simultaneously making a total of 75 larvae for each concentration of a particular insecticide.

The dead and moribund larvae were counted and recorded after $24 \mathrm{~h}$ of exposure. The larvae were touch with a glass rod to assess their survival status. Control experiments were run simultaneously by substituting insecticidal solution with ethanol. 


\subsection{Data Analysis}

The bioassays resulting in more than $20 \%$ larval mortality or pupae formation in control indicated the inappropriate selection of larvae and thus were discarded and run again. However, if 5-20\% larval mortality was obtained in control assays, it was corrected by Abbott's formula [28].

$$
\% \text { corrected mortality }=\frac{\% \text { Test mortality }-\% \text { Control mortality }}{100-\% \text { Control mortality } 100}
$$
$100-\%$ Control mortality

The concentration-response data obtained and recorded was then analyzed by probit-regression analysis using a statistical software program SPSS 19.0. The median lethal concentrations $\left(\mathrm{LC}_{50}\right)$ values, $90 \%$ lethal concentration values $\left(\mathrm{LC}_{90}\right)$, their 95\% Confidence Intervals (CI), slope, Standard Error (SE), Regression Coefficient (RC)/Slope and chi square values were calculated. The $\mathrm{LC}_{50}$ values were considered significantly different when their $95 \% \mathrm{CI}$ did not overlap.

\section{RESULTS}

The larvicidal potentialities of thirteen insecticides belonging to different classes - Organochlorines (Malathion, Fenitrothion), Organophosphates (Endosulphan, Lindane), Carbamates (Carbofuran, Fenobucarb), Pyrethroids (Deltamethrin, Lambda-cyhalothrin, Alpha-cypermethrin, Permethrin), Neonicotinoid (Acetamiprid), Avermectin (Emamectin benzoate) and Secondary metabolite (Berberine) - evaluated against early fourth instar of Ae. aegypti L are presented in Tables $\mathbf{2}$ to $\mathbf{6}$. The results obtained clearly show the maximum efficacy of alpha-cypermethrin among all the insecticides investigated revealing lowest $\mathrm{LC}_{50}$ value of $0.00048 \mathrm{ppm}$. Among the two organochlorines tested, lindane exhibited five times higher toxicity than endosulphan which caused 50\% larval mortality at 0.39 ppm (Table 2). Similarly, among the OPs, fenitrothion was found to be highly toxic while malathion showed moderate toxicity (Table 3). It is also evident from the data that Ae. aegypti early fourth instars exhibited more susceptibility towards OPs as compared to OCls.

Table 2. Larvicidal activity of organochlorines against early fourth instars of Aedes aegypti.

\begin{tabular}{|c|c|c|c|c|c|}
\hline S. No. & Insecticides & $\mathbf{L C}_{50}$ in ppm & $\mathrm{LC}_{90}$ in ppm & $\begin{array}{c}\chi^{2} \\
\text { (df) }\end{array}$ & Slope \pm SE \\
\hline 1 & Lindane & $\begin{array}{c}0.0832 \\
(0.0662-0.1014)\end{array}$ & $\begin{array}{c}0.4011 \\
(0.3062-0.5819)\end{array}$ & $5.29(7)$ & $1.737 \pm 0.28$ \\
\hline 2 & Endosulphan & $\begin{array}{c}0.3987 \\
(0.2863-0.5085)\end{array}$ & $\begin{array}{c}0.7163 \\
(0.5552-1.1754)\end{array}$ & $9.64(5)$ & $1.29 \pm 0.65$ \\
\hline
\end{tabular}

$\mathrm{LC}_{50}$ - Lethal Concentration that kills $50 \%$ of the exposed larvae, $\mathrm{LC}_{90}$ - Lethal Concentration that kills $90 \%$ of the exposed larvae; Values in parentheses indicate the lower and upper $95 \%$ fiducial limits; $\chi^{2}=$ Chi-square, S.E. $=$ Standard Error, $\mathrm{df}=\mathrm{degree}$ of freedom.

Table 3. Larvicidal activity of organophosphates against early fourth instars of Aedes aegypti

\begin{tabular}{|c|c|c|c|c|c|}
\hline S. No. & Insecticides & $\mathbf{L C}_{\mathbf{5 0}}$ in ppm & $\mathbf{L C}_{\mathbf{9 0}}$ in ppm & $\begin{array}{c}\chi^{\mathbf{2}} \\
(\mathbf{d f})\end{array}$ & $\begin{array}{c}0.1058 \\
\text { Slope } \pm \text { SE } \\
(0.0930-0.1252)\end{array}$ \\
\hline $\mathbf{1}$ & Malathion & $\begin{array}{c}0.0548 \\
(0.0472-0.0620)\end{array}$ & $\begin{array}{c}0.00392 \\
(0.0016-0.3509)\end{array}$ & $5.5369 \pm 0.72$ \\
\hline $\mathbf{2}$ & Fenitrothion & $\begin{array}{c}0.00063 \\
(0.0003-0.0013)\end{array}$ & $0.084(4)$ & $0.8086 \pm 0.36$ \\
\hline
\end{tabular}

$\mathrm{LC}_{50}$ - Lethal Concentration that kills $50 \%$ of the exposed larvae, $\mathrm{LC}_{90}$ - Lethal Concentration that kills $90 \%$ of the exposed larvae; Values in parentheses indicate the lower and upper $95 \%$ fiducial limits; $\chi^{2}=$ Chi-square, S.E. $=$ Standard Error, $\mathrm{df}=\mathrm{degree}$ of freedom

The larvicidal bioassay with carbamates against Dengue vector revealed less efficacy as compared to OCls and OPs. Moreover, both the carbamates used; carbofuran and fenobucarb, were found almost equally effective resulting in respective $\mathrm{LC}_{50}$ value of $0.52 \mathrm{ppm}$ to $0.59 \mathrm{ppm}$ (Table 4).

Table 4. Larvicidal activity of carbamates against early fourth instars of Aedes aegypti.

\begin{tabular}{|c|c|c|c|c|c|}
\hline S. No. & Insecticides & $\mathbf{L C}_{\mathbf{5 0}}$ in $\mathbf{~ p p m}$ & $\mathbf{L C}_{\mathbf{9 0}}$ in ppm & $\begin{array}{c}\chi^{2} \\
(\mathbf{d f})\end{array}$ & Slope \pm SE \\
\hline $\mathbf{1}$ & Carbofuran & $\begin{array}{c}0.5253 \\
(0.4642-0.5888)\end{array}$ & $\begin{array}{c}1.0576 \\
(0.9006-1.3521)\end{array}$ & $\begin{array}{c}5.888 \\
(3)\end{array}$ & $4.0612 \pm 0.55$ \\
\hline
\end{tabular}


(Table 4) contd.....

\begin{tabular}{|c|c|c|c|c|c|}
\hline S. No. & Insecticides & $\mathrm{LC}_{50}$ in ppm & $\mathrm{LC}_{90}$ in ppm & $\begin{array}{l}\chi^{2} \\
(\mathrm{df})\end{array}$ & Slope \pm SE \\
\hline 2 & Fenobucarb & $\begin{array}{c}0.5914 \\
(0.5241-0.6510)\end{array}$ & $\begin{array}{c}1.0861 \\
(0.9763-1.2537)\end{array}$ & $\begin{array}{c}3.575 \\
(5)\end{array}$ & $4.3071 \pm 0.76$ \\
\hline
\end{tabular}

$\mathrm{LC}_{50}$ - Lethal Concentration that kills $50 \%$ of the exposed larvae, $\mathrm{LC}_{90}$ - Lethal Concentration that kills $90 \%$ of the exposed larvae; Values in parentheses indicate the lower and upper 95\% fiducial limits; $\chi^{2}=$ Chi-square, S.E. $=$ Standard Error, $\mathrm{df}=\mathrm{degree}$ of freedom.

In the present study, four pyrethroids were also investigated for their efficiency against larvae of Dengue fever vector. The larvae showed high susceptibility towards pyrethroids as compared to rest of the investigated classes of insecticides. The results revealed that permethrin was least toxic out of the four pyrethroids possessing $\mathrm{LC}_{50}$ of 0.007 ppm. The alpha-cypermethrin, which exhibited comparable efficacy to fenitrothion, was observed to be 2-fold more effective than deltamethrin and lambda-cyhalothrin whereas it showed 13-fold more larvicidal efficacy than permethrin. Moreover, the $\mathrm{LC}_{90}$ values of three pyrethroids; deltamethrin, lambda-cyhalothrin and alpha-cypermethrin were found to be overlapping except permethrin which showed an $\mathrm{LC}_{90}$ of 0.1 ppm (Table 5 and Fig. 2).

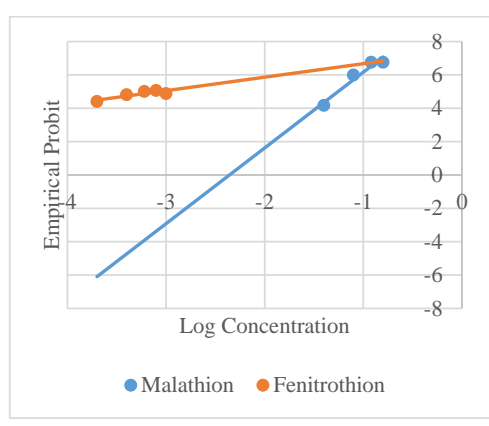

(a)

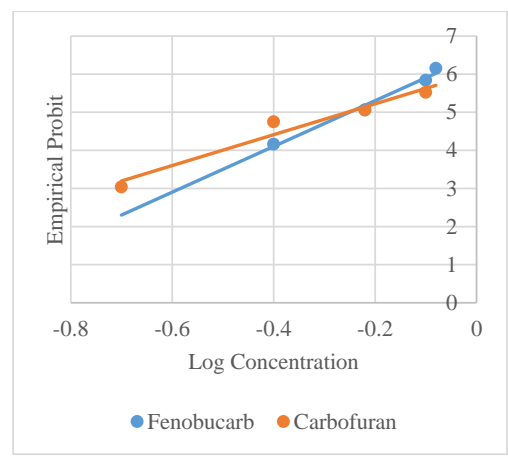

(c)

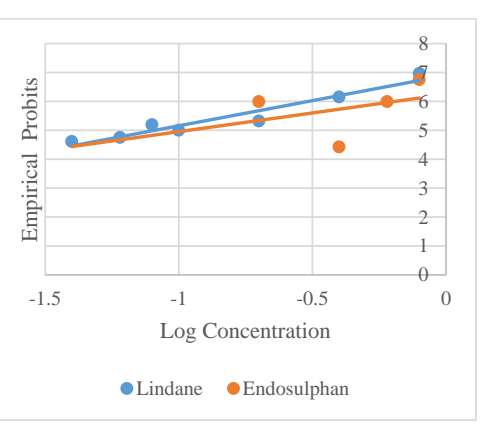

(b)

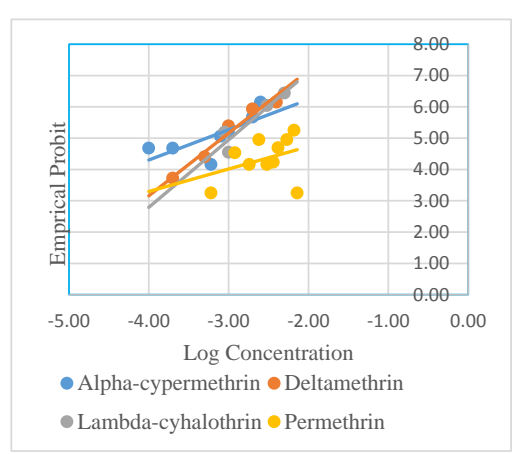

(d)

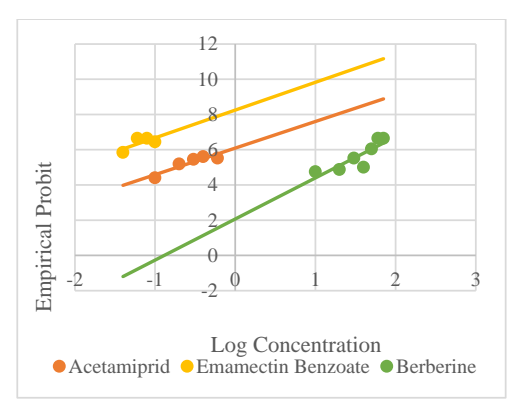

(e)

Fig. (2). Dosage-mortality regression lines obtained when larvae of Aedes aegypti were assayed with (a) Organochlorines, (b) Organophosphates, (c) Carbamates, (d) Pyrethroids and (e) Acetamiprid, Emamectin benzoate and Berberine. 
Table 5. Larvicidal activity of pyrethroids against early fourth instars of Aedes aegypti.

\begin{tabular}{|c|c|c|c|c|c|}
\hline S. No. & Insecticides & $\mathrm{LC}_{50}$ in $\mathrm{ppm}$ & $\mathbf{L C}_{90}$ in ppm & $\begin{array}{c}\chi^{2} \\
\text { (df) }\end{array}$ & Slope \pm SE \\
\hline 1 & Deltamethrin & $\begin{array}{c}0.0008 \\
(0.0006-0.0010)\end{array}$ & $\begin{array}{c}0.0034 \\
(0.0025-0.0054)\end{array}$ & $1.615(4)$ & $2.003 \pm 0.35$ \\
\hline 2 & Lambda-cyhalothrin & $\begin{array}{c}0.0009 \\
(0.0004-0.0014)\end{array}$ & $\begin{array}{c}0.0035 \\
(0.0022-0.0109)\end{array}$ & $6.458(5)$ & $2.174 \pm 0.39$ \\
\hline 3 & Alpha-cypermethrin & $\begin{array}{c}0.0005 \\
(0.0002-0.0009)\end{array}$ & $\begin{array}{c}0.0037 \\
(0.0016-0.0450)\end{array}$ & $23.175(8)$ & $0.966 \pm 0.20$ \\
\hline 4 & Permethrin & $\begin{array}{c}0.0074 \\
(0.0050-0.0150)\end{array}$ & $\begin{array}{c}0.0817 \\
(0.0281-1.5081)\end{array}$ & $\begin{array}{c}13.372 \\
(8)\end{array}$ & $1.5145 \pm 0.28$ \\
\hline
\end{tabular}

$\mathrm{LC}_{50}$ - Lethal Concentration that kills $50 \%$ of the exposed larvae, $\mathrm{LC}_{90}$ - Lethal Concentration that kills $90 \%$ of the exposed larvae; Values in parentheses indicate the lower and upper $95 \%$ fiducial limits; $\chi^{2}=$ Chi-square, S.E. $=$ Standard Error, $\mathrm{df}=\mathrm{degree}$ of freedom.

Bioassays with neonicotinoids evidenced their considerable efficacy against early fourth instars of Ae. aegypti. Acetamiprid showed a moderate $\mathrm{LC}_{50}$ and $\mathrm{LC}_{90}$ value of $0.1879 \mathrm{ppm}$ and $1.3155 \mathrm{ppm}$ (Table 6). Emamectin benzoate, an avermectin was found to be 14 times more effective than acetamiprid against larvae of Ae. aegypti exhibiting $\mathrm{LC}_{50}$ of $0.013 \mathrm{ppm}$ and $\mathrm{LC}_{90}$ of $0.060 \mathrm{ppm}$. Berberine, an alkaloid belonging to secondary metabolite, which is an active component inplant like Argemone mexicana, when assayed for larvicidal potential did not show appreciable toxicity revealing $\mathrm{LC}_{50}$ of $20.24 \mathrm{ppm}$ and $\mathrm{LC}_{90}$ of $62.60 \mathrm{ppm}$ (Table 6).

Table 6. Larvicidal activity of a neonicotinoid, bioactive plant metabolite and an avermectin against early fourth instars of Aedes aegypti.

\begin{tabular}{|c|c|c|c|c|c|}
\hline S. No. & Insecticides & $\mathbf{L C}_{\mathbf{5 0}}$ in $\mathbf{~ p p m}$ & $\mathbf{L C}_{\mathbf{9}}$ in ppm & $\begin{array}{c}\chi^{\mathbf{2}} \\
(\mathbf{d f})\end{array}$ & Slope \pm SE \\
\hline $\mathbf{1}$ & Acetamiprid & $\begin{array}{c}0.1879 \\
(0.1193-0.2477)\end{array}$ & $\begin{array}{c}1.3154 \\
(0.7586-5.2407)\end{array}$ & $1.698(3)$ & $1.516 \pm 0.49$ \\
\hline $\mathbf{2}$ & Berberine & $\begin{array}{c}20.2432 \\
(11.1741-29.3252)\end{array}$ & $\begin{array}{c}62.6057 \\
(41.4218-156.8984)\end{array}$ & $\begin{array}{c}17.044 \\
(7)\end{array}$ & $2.339 \pm 0.35$ \\
\hline $\mathbf{3}$ & Emamectin benzoate & $\begin{array}{c}0.0128 \\
(0.00001-0.0294)\end{array}$ & $\begin{array}{c}0.05928 \\
(0.0315-0.0992)\end{array}$ & $\begin{array}{c}0.741 \\
(3)\end{array}$ & $1.569 \pm 1.11$ \\
\hline
\end{tabular}

$\mathrm{LC}_{50}$ - Lethal Concentration that kills $50 \%$ of the exposed larvae, $\mathrm{LC}_{90}$ - Lethal Concentration that kills $90 \%$ of the exposed larvae; Values in parentheses indicate the lower and upper $95 \%$ fiducial limits; $\chi^{2}=$ Chi-square, S.E. $=$ Standard Error, $\mathrm{df}=$ degree of freedom.

Comparative toxicity of all the thirteen insecticides used in the present study revealed that exposure to 2 ppm of all the insecticides caused $100 \%$ larval mortality except berberine which was found ineffective. (Fig. 3).

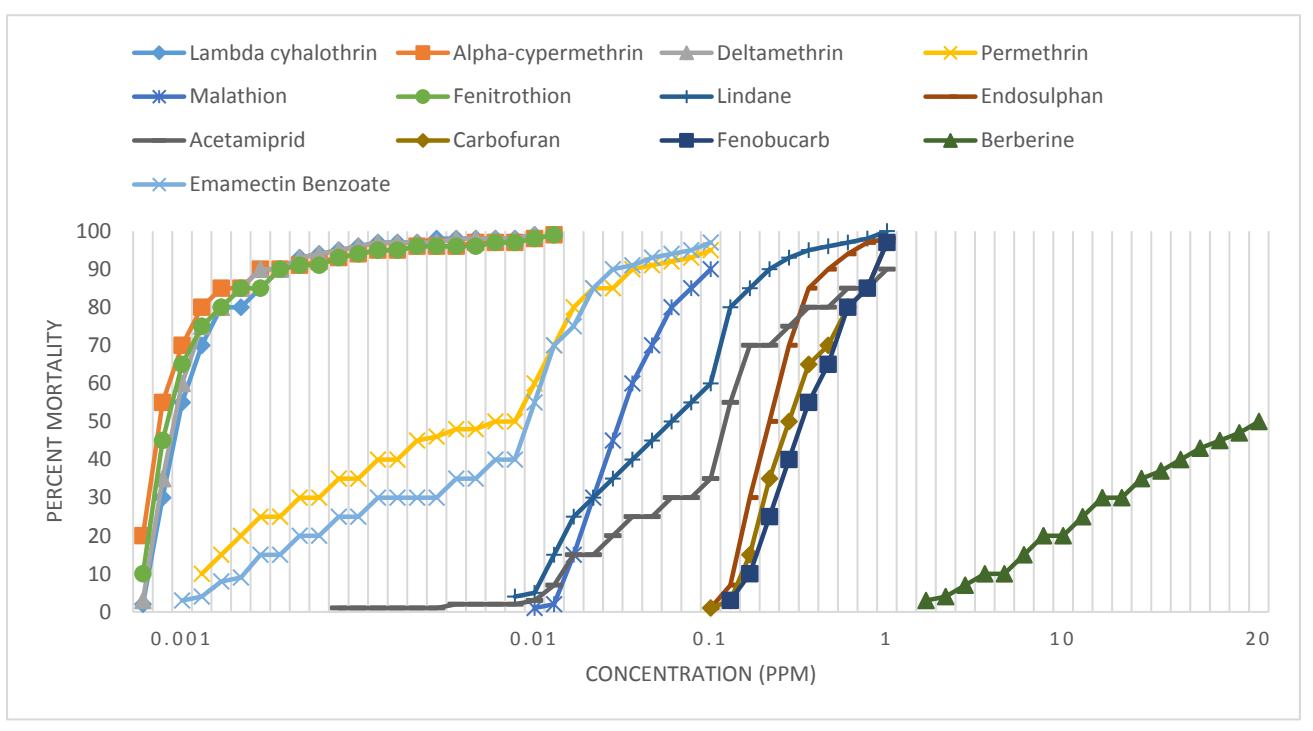

Fig. (3). Comparative percent mortality of Aedes aegypti early fourth instars exposed to various insecticides for $24 \mathrm{~h}$. 


\section{DISCUSSION}

Different classes of insecticides; such as pyrethroids, organophosphate, organochlorines, carbamates have been used from decades to control mosquitoes. The extensive use of these insecticides has caused the problem of resistance in mosquito vectors. Thus, evaluation of susceptibility of different synthetic insecticides for selection of the most efficacious compound is an important step for devising strategy for effective mosquito control.

In the present study an attempt was made to assess the larvicidal activity of 13 different insecticides belonging to 7 different classes; namely Pyrethroids (Deltamethrin, Alpha-Cypermethrin, Lambda-Cyhalothrin and Permethrin), Organophosphates (Malathion and Fenitrothion), Organochlorines (Endosulphan and Lindane), Carbamates (Carbofuran and Fenobucarb), Neonicotinoid (Acetamiprid), Bioactive plant metabolite (Berberine) and Avermectin (Emamectin benzoate).

Our results showed that alpha-cypermethrin exhibited maximum toxicity against early fourth instars of Ae. aegypti as compared to other pyrethroids as well as other groups of insecticides which indicates it to be the most promising agent to be incorporated in the integrated vector management programmes. It is well known that pyrethroids are the sodium channel modulators that are being extensively used for the control of mosquitoes. Further, they are highly recommended by WHO for mosquito management due to their low mammalian toxicity and environmental safety [17]. Earlier, Kumar et al. [18] revealed much lower $\mathrm{LC}_{50}$ value $(0.000118 \mathrm{ppm})$ when larvae of Dengue fever vector were assayed with deltamethrin. They also reported development of 703 -fold deltamethrin resistance after continuous exposure till 40 successive [18]. A study conducted in Cochin found that Ae. aegypti and Ae. albopictus were resistant to DDT and dieldrin, but susceptible to propoxur, fenitrothion, malathion, deltamethrin, permethrin and lambdacyhalothrin [29]. The investigations in Saudi Arabia reported comparable results when lambda-cyhalothrin was assayed against Ae. aegypti larvae resulting in $\mathrm{LC}_{50}$ of $0.007 \mathrm{ppm}$ [30]. In Nigeria, larval bioassays carried out against IV instar larvae of Ae. aegypti and Cx. quinquefasciatus with dieldrin, dichlorvos and permethrin resulted in respective $\mathrm{LC}_{50}$ values of $0.48,37.09$ and $0.29 \mu \mathrm{g} / \mathrm{L}$ and $0.11,10.05$ and $0.05 \mu \mathrm{g} / \mathrm{L}$ [31] clearly indicating higher efficacy of pyrethroids as compared to other groups of insecticides.

Our results showed comparatively less toxicity of deltamethrin and lambda-cyhalothrin among all four tested pyrethroids though they were found to be more effective than rest of the insecticides tested except fenitrothion. The reduced susceptibility to these pyrethroids may possibly be linked with its extensive usage at broader scale for the control of Dengue fever vectors [18]. Our results suggest to use alternative pyrethroids for effective control of $A e$. aegypti. The present bioassays also showed relatively low efficacy of organochlorines as compared to pyrethroids and organophosphates, but showed higher cidal value with respect to carbamates. The lindane was found to be five times more toxic than endosulphan. These insecticides have been in use since decades for control of various insect pests. Consequently, mosquitoes seem to have develop resistance against them making them less effective. Also, similar mode of action of organochlorines and pyrethroids often results in cross-resistance and is the possible cause of gradually reduced susceptibility to these insecticides.

Our investigations also showed much higher larval toxicity of fenitrothion as compared to another organophosphate, malathion; organochlorines, carbamates and most of the pyrethroids. The low toxicity of malathion may be attributed to its widespread application in mosquito management programmes since decades [29]. These results recommend to utilize alternate insecticides against which larvae of Dengue fever vector are susceptible. In Western Venezuela; the larvicidal activity of malathion was found in range of $1.6 \mathrm{ppm}$ to $3.49 \mathrm{ppm}$ against Ae. aegypti; much higher than obtained by us [32].

The neonicotinoids function as the nicotinic acetylcholinesterase inhibitors in the insect nervous system [21]. Acetamiprid has been reported to be moderately toxic against invertebrates and nontoxic to non-target organism [33]. Our results showed moderate toxicity of acetamiprid resulting in $\mathrm{LC}_{50}$ and $\mathrm{LC}_{90}$ values of $0.188 \mathrm{ppm}$ and $1.315 \mathrm{ppm}$ against early fourth instars of Ae. aegypti. Comparatively low toxicity of acetamiprid could be linked with its widespread usage in the management programs of bed bugs and the other insect pests [34]. The evaluation of the efficacy of different neonicotinoids against three different strains of mosquitoes revealed efficacy of imidacloprid against Ae. aegypti with much higher lethal values; $\mathrm{LC}_{50}$ and $\mathrm{LC}_{90}$ as $0.558 \mathrm{ppm}$ and $6.135 \mathrm{ppm}$ [35].

In case of other relatively new insecticides, emamectin benzoate, a GABA receptors stimulator causing increase in membrane chloride ion permeability was found to exhibit high toxicity against Ae. aegypti larvae rendering it a suitable option in the Dengue vector management. It resulted in higher larval mortality at lower dosages than caused by carbamates, endosulfan, acetamiprid and berberine. However, it extended much less toxicity when compared to that of 
pyrethroids. James et al. [36] had examined the efficacy of 3 different avermectins against both susceptible and insecticide-resistant laboratory strains of blowfly, Lucilia cuprina. All 3 compounds were found more toxic to blowfly larvae as compared to the OP compound, diazinon. Moreover, no significant cross-resistance to avermectins has been reported in houseflies resistant to dieldrin, DDT, diazinon or permethrin making it an efficient option [37].

The range of response to various insecticides in Ae. aegypti larvae could represent the natural variation between essentially susceptible populations. Consequently, the information presented here may be used as baseline data to monitor development of resistance in mosquitoes. When berberine, an alkaloid present in variety of plants like Argemone mexicana was tested against the larvae of Dengue fever vecto, it was found quite ineffective. The assays revealed $62 \mathrm{ppm}$ as $\mathrm{LC}_{90}$ value which was quite high as compared to the results obtained by Philogène et al. [38]. They also showed that mosquito larvae that were treated with $10 \mathrm{ppm}$ berberine plus near UV for 24 hours, exhibited the $\mathrm{LC}_{50}$ of 8.8 ppm compared to 250 ppm for dark controls.

Insecticide resistance has been a problem in all insect groups that serve as vectors of emerging diseases. Although mechanisms by which insecticides become less effective are similar across all vector taxa, each resistance problem is potentially unique and may involve a complex pattern of resistance foci. The main defense against resistance is close surveillance of the susceptibility of vector populations [39]. It is generally believed that employing an insecticide with highest efficacy would give best results in pest management programmes. However, the long-term and continued utilization of the only one insecticide could result in the development of resistance and failure of the management program. It is recommended that most toxic insecticides from groups with different modes of action should be used in rotation to prolong the efficacy of insecticides. However, the success of the insecticide rotation scheme depends upon the mode of action, mechanism of development of resistance and cross-resistance potential that are needed to be confirmed in the future to prolong the efficacy of these insecticides.

\section{CONCLUSION}

Our investigations showed the variable susceptibility in Ae. aegypti larvae to different insecticides and demonstrates a better understanding about their susceptibility towards traditionally used and newly introduced insecticides. However, variations in insecticide susceptibility may be attributed to a variety of factors; heterogeneity of population, extent of usage and mode of action of insecticides, development of resistance, cross-resistance patterns, etc. which need to be investigated comprehensively to formulate and recommend the measures for insecticide resistance management.

\section{ETHICS APPROVAL AND CONSENT TO PARTICIPATE}

Not applicable.

\section{HUMAN AND ANIMAL RIGHTS}

No animals/humans were used for studies that are the basis of this research.

\section{CONSENT FOR PUBLICATION}

Not applicable.

\section{CONFLICT OF INTEREST}

The authors declare no conflict of interest, financial or otherwise.

\section{ACKNOWLEDGEMENTS}

The authors are thankful to the Council of Scientific and Industrial Research (CSIR), New Delhi for providing financial assistance to carry the experiment. The authors extend thanks to Dr. Savithri Singh, Principal Acharya Narendra Dev College for providing laboratory and culture facilities to conduct the experiments.

\section{REFERENCES}

[1] Ghosh A, Chowdhury N, Chandra G. Plant extracts as potential mosquito larvicides. Indian J Med Res 2012; 135(5): 581-98. [PMID: 22771587]

[2] Tolle MA. Mosquito-borne diseases. Curr Probl Pediatr Adolesc Health Care 2009; 39(4): 97-140. [http://dx.doi.org/10.1016/j.cppeds.2009.01.001] [PMID: 19327647] 
[3] World Health Organization. The Weekly Epidemiological Record (WER). WHO. [Accessed 11 Mar 2018]. Available from: http://www.who.int/wer/en/

[4] Bhatt S, Gething PW, Brady OJ, et al. The global distribution and burden of dengue. Nature 2013; 496(7446): 504-7. [http://dx.doi.org/10.1038/nature12060] [PMID: 23563266]

[5] Brady OJ, Gething PW, Bhatt S, et al. Refining the global spatial limits of dengue virus transmission by evidence-based consensus. PLoS Negl Trop Dis 2012; 6(8): e1760.

[http://dx.doi.org/10.1371/journal.pntd.0001760] [PMID: 22880140]

[6] National Vector Borne Disease Control Programme (NVBDCP). [Accessed February 28, 2018]. Dengue Cases and Deaths in the Country since 2010. http://nvbdcp.gov.in/den-cd.html

[7] Rajmohan D, Ramswamy M. Evaluation of larvicidal activity of the leaf extract of a weed plant, Ageratina adenophora against two important species of mosquito, Aedes aegypti and Culex quinquefasciatus. Afr J Biotechnol 2007; 6: 631-8.

[8] Kumar S, Warikoo R, Mishra M, Samal RR. Shrankhla, Panmei K, Dagar VS, Sharma A. Impact of Ocimum basilicum leaf essential oil on the survival and behavior of an Indian strain of Dengue vector, Aedes aegypti (L). Vector Biol J 2017; 2: 1-6. [http://dx.doi.org/10.4172/2473-4810.1000122]

[9] Moore MT, Cooper CM, Smith S Jr, et al. Mitigation of two pyrethroid insecticides in a Mississippi Delta constructed wetland. Environ Pollut 2009; 157(1): 250-6. [http://dx.doi.org/10.1016/j.envpol.2008.07.025] [PMID: 18789833]

[10] US Environmental Protection Agency. Factsheet-clothianidin 2003; 19. Available from: http:// www3.epa.gov/ pesticides/ chem._search/ reg_actions/registration/ fs_PC-044309_30-may-03.pdfQ

[11] Bonner MR, Coble J, Blair A, et al. Malathion exposure and the incidence of cancer in the agricultural health study. Am J Epidemiol 2007; 166(9): 1023-34.

[http://dx.doi.org/10.1093/aje/kwm182] [PMID: 17720683]

[12] Liu N, Xu Q, Zhu F, Zhang L. Pyrethroid resistance in mosquitoes. Insect Sci 2006; 13: 59-166. [http://dx.doi.org/10.1111/j.1744-7917.2006.00078.x]

[13] Kumar S, Wahab N, Mishra M, Warikoo R. Evaluation of 15 local plant species as larvicidal agents against an Indian strain of Dengue fever mosquito, Aedes aegypti L. (Diptera: Culicidae). Front Physiol 2012; 3: 104. [http://dx.doi.org/10.3389/fphys.2012.00104] [PMID: 22536188]

[14] Sharma A, Kumar S, Tripathi P. Evaluation of the larvicidal efficacy of five indigenous weeds against an Indian strain of Dengue vector, Aedes aegypti L. (Diptera: Culicidae). J Parasitol Res 2016; 2016: 2857089.

[http://dx.doi.org/10.1155/2016/2857089] [PMID: 26941996]

[15] Elliott M, Janes NF, Potter C. The future of pyrethroids in insect control. Annu Rev Entomol 1978; 23: 443-69. [http://dx.doi.org/10.1146/annurev.en.23.010178.002303]

[16] Rayman RB. Aircraft disinsection. Aviat Space Environ Med 2006; 77(7): 733-6. [PMID: 16856359]

[17] Raghavendra K, Verma V, Srivastava HC, Gunasekaran K, Sreehari U, Dash AP. Persistence of DDT, malathion \& deltamethrin resistance in Anopheles culicifacies after their sequential withdrawal from indoor residual spraying in Surat district, India. Indian J Med Res 2010; 132: 260-4.

[PMID: 20847371]

[18] Kumar S, Thomas A, Samuel T, Sahgal A, Verma A, Pillai MKK. Diminished reproductive fitness associated with the deltamethrin resistance in an Indian strain of dengue vector mosquito, Aedes aegypti L. Trop Biomed 2009; 26(2): 155-64.

[PMID: 19901902]

[19] Luo Y, Zhang M. Environmental modeling and exposure assessment of sediment-associated pyrethroids in an agricultural watershed. PLoS One 2011; 6(1): e15794 [http://dx.doi.org/10.1371/journal.pone.0015794] [PMID: 21246035]

[20] Zhu Y, Loso MR, Watson GB, et al. Discovery and characterization of sulfoxaflor, a novel insecticide targeting sap-feeding pests. J Agric Food Chem 2011; 59(7): 2950-7. [http://dx.doi.org/10.1021/jf102765x] [PMID: 21105655]

[21] Tomizawa M, Casida JE. Neonicotinoid insecticide toxicology: Mechanisms of selective action. Annu Rev Pharmacol Toxicol 2005; 45: 247-68.

[http://dx.doi.org/10.1146/annurev.pharmtox.45.120403.095930] [PMID: 15822177]

[22] Strong L, Brown TA. Avermectins in insect control and biology: A review. Bull Entomol Res 1987; 77: $357-89$. [http://dx.doi.org/10.1017/S0007485300011846]

[23] Campbell WC, Fisher MH, Stapley EO, Albers-Schönberg G, Jacob TA. Ivermectin: A potent new antiparasitic agent. Science 1983; 221(4613): 823-8. [http://dx.doi.org/10.1126/science.6308762] [PMID: 6308762]

[24] Hotson IK. The avermectins: A new family of antiparasitic agents. J S Afr Vet Assoc 1982; 53(2): 87-90. 
[PMID: 6750121]

[25] World Health Organization (WHO). Guidelines for laboratory and field testing of mosquito larvicide 2005; 1-39. Retrieved from http://WHO/CDC/WHOPES/GCDPP/Geneva: WHO

[26] Warikoo R, Ray A, Sandhu JK, Samal R, Wahab N, Kumar S. Larvicidal and irritant activities of hexane leaf extracts of Citrus sinensis against dengue vector Aedes aegypti L. Asian Pac J Trop Biomed 2012; 2(2): 152-5. [http://dx.doi.org/10.1016/S2221-1691(11)60211-6] [PMID: 23569887]

[27] Kumar S, Mishra M, Wahab N, Warikoo R. Larvicidal, repellent and irritant potential of the seed-derived essential oil of Apium graveolens against Dengue Vector, Aedes aegypti L. (Diptera: Culicidae). Front Public Health 2014; 2: 147. [http://dx.doi.org/10.3389/fpubh.2014.00147] [PMID: 25279371]

[28] Abbott WS. A method of computing the effectiveness of an insecticide. J Econ Entomol 1925; 18: 265-7. [http://dx.doi.org/10.1093/jee/18.2.265a]

[29] Sharma SN, Saxena VK, Lal S. Study on susceptibility status in aquatic and adult stages of Aedes aegypti and Ae. albopictus against insecticides at international airports of south India. J Commun Dis 2004; 36(3): 177-81. [PMID: 16509254]

[30] Thbiani ALA, Hamady D, Ahmad AH, et al. Insecticides susceptibility of the dengue vector Aedes aegypti (Diptera: Culicidae) in Makkah city, Saudi Arabia. Asian Pac J Trop Biomed 2004; 1: 94-9.

[31] Abba U, Larit SK, Tati AH. Susceptibility of mosquito larvae to conventional insecticides in a tropical arid ecosystem. Anim Res Int 2017; 3: 407-9.

[32] Alvarez LC, Ponce G, Oviedo M. Lopez, Band Flores, AE. Resistance to malathion and deltamethrin in Aedes aegypti (Diptera: Culicidae) from Western Venezuela. J Med Entomol 2013; 50: 1031-9. [http://dx.doi.org/10.1603/ME12254] [PMID: 24180108]

[33] Mahmoud MF, Loutfy N. Uses and environmental pollution of biocides. In: Pesticides Evaluation of Environmental Pollution. 2012; 11: p. 659.

[34] Corbel V, N'Guessan R, Brengues C, et al. Multiple insecticide resistance mechanisms in Anopheles gambiae and Culex quinquefasciatus from Benin, West Africa. Acta Trop 2007; 101(3): 207-16. [http://dx.doi.org/10.1016/j.actatropica.2007.01.005] [PMID: 17359927]

[35] Uragayala S, Verma V, Natarajan E, Velamuri PS, Kamaraju R. Adulticidal \& larvicidal efficacy of three neonicotinoids against insecticide susceptible \& resistant mosquito strains. Indian J Med Res 2015; 142(Suppl.): S64-70. [http://dx.doi.org/10.4103/0971-5916.176624] [PMID: 26905244]

[36] James PS, Picton J, Riek RF. Insecticidal activity of the avermectins. Vet Rec 1980; 106(3): 59. [http://dx.doi.org/10.1136/vr.106.3.59-a] [PMID: 7361432]

[37] Roush RT, Wright JE. Abamectin: Toxicity to house flies (Diptera: Muscidae) resistant to synthetic organic insecticides. J Econ Entomol 1986; 79(3): 562-4.

[http://dx.doi.org/10.1093/jee/79.3.562] [PMID: 3722588]

[38] Philogène BJ, Arnason JT, Towers GH, et al. Berberine: A naturally occurring phototoxic alkaloid. J Chem Ecol 1984; 10(1): 115-23. [http://dx.doi.org/10.1007/BF00987648] [PMID: 24318233]

[39] Brogdon WG, McAllister JC. Insecticide resistance and vector control. Emerg Infect Dis 1998; 4(4): 605-13. [http://dx.doi.org/10.3201/eid0404.980410] [PMID: 9866736]

\section{(C) 2018 Samal and Kumar.}

This is an open access article distributed under the terms of the Creative Commons Attribution 4.0 International Public License (CC-BY 4.0), a copy of which is available at: https://creativecommons.org/licenses/by/4.0/legalcode. This license permits unrestricted use, distribution, and reproduction in any medium, provided the original author and source are credited. 